\title{
Relationship Between Circulating Tumor Cells and Annexin A2 in Early Breast Cancer Patients
}

\author{
BRANISLAV BYSTRICKY ${ }^{1,2^{*}}$, ZUZANA CIERNA ${ }^{3 *}$, GABRIELA SIEBEROVA $^{4}$, PAVOL JANEGA ${ }^{3,5}$, \\ MARIAN KARABA ${ }^{4,6}$, GABRIEL MINARIK $^{7}$, JURAJ BENCA ${ }^{4,6,8}$, TATIANA SEDLACKOVA ${ }^{7}$, \\ SILVIA JURISOVA ${ }^{1,4}$, PAULINA GRONESOVA ${ }^{9}$, DANIEL PINDAK ${ }^{4,6}$, \\ JAN MACUCH ${ }^{4}$, JOZEF MARDIAK ${ }^{1,4}$ and MICHAL MEGO ${ }^{1,4,10}$ \\ ${ }^{1}$ 2nd Department of Medical Oncology, Faculty of Medicine, Comenius University, Bratislava, Slovakia; \\ ${ }^{2}$ Oncology Department Faculty Hospital Trencin, Trencin, Slovakia; \\ ${ }^{3}$ Department of Pathology, Faculty of Medicine, Comenius University, Bratislava, Slovakia; \\ ${ }^{4}$ National Cancer Institute, Bratislava, Slovakia; \\ ${ }^{5}$ Institute of Normal and Pathological Physiology, Faculty of Medicine, Comenius University, Bratislava, Slovakia; \\ ${ }^{6}$ Department of Surgery, Slovak Medical University, Bratislava, Slovakia; \\ ${ }^{7}$ Institute of Molecular Biomedicine, Faculty of Medicine, Comenius University, Bratislava, Slovakia; \\ ${ }^{8}$ Department of Medicine, St. Elizabeth University, Bratislava, Slovakia; \\ ${ }^{9}$ Cancer Research Institute BMC, Slovak Academy of Sciences, Bratislava, Slovakia; \\ ${ }^{10}$ Translational Research Unit, Bratislava, Slovakia
}

\begin{abstract}
Background/Aim: Annexin A2 (ANXA2) is a phospholipid-binding protein involved in fibrinolysis, cell proliferation, migration and metastatic dissemination. Circulating tumor cells (CTCs) are cells responsible for tumor dissemination and have a prognostic value in several types of cancers including breast cancer. Previously, we found correlation between CTCs and activation of coagulation. This study aimed to correlate CTCs with ANXA2 expression on CTCs, tumor cells and tumor associated stroma in primary breast cancer (PBC) patients. Patients and Methods: This prospective study included 101 PBC patients treated by primary surgery. CTCs were detected by quantitative realtime polymerase chain reaction ( $q R T-P C R)$ assay for the expression of epithelial (CK19) or epithelial-mesenchymal transition (EMT) genes [TWIST1, SNAI1, SNAI2, zinc finger E-box-binding homeobox 1 (ZEB1)]. ANXA2 expression on CTCs was detected by qRT-PCR, while expression of ANXA2 in tumor specimen was evaluated by immunohistochemistry and expressed by a weighted histoscore, evaluating both the
\end{abstract}

\footnotetext{
*These Authors contributed equally to this study.

Correspondence to: Michal Mego, 2nd Department of Medical Oncology, Comenius University, Faculty of Medicine and National Cancer Institute, Klenova 1, 83310 Bratislava, Slovakia. Tel: +421 259378366, Fax: +421 254774943, e-mail: misomego@gmail.com
}

Key Words: Circulating tumor cells, annexin A2, breast cancer. percentage of positive cells and the intensity of membrane and cytoplasmic staining. Results of hormone receptors, HER2 status, B-cell lymphoma 2 (bcl-2) protein expression and protein $p 53$ were reported as either positive or negative on histopathology report without further quantification. Results: CTCs were detected in $24.8 \%$ patients. Patients with epithelial CTCs had a significantly higher ANXA2 expression on CTCs than those of patients without CTCs $(p=0.01)$. There was no association between CTCs and ANXA2 protein expression in tumor cells. However, patients, whom CTCs with EMT phenotype were detected in, had higher ANXA2 expression in tumor stroma when compared to those with absent EMT CTCs ( $p=0.04)$. Hormone-negative tumors had significantly higher ANXA2 expression in tumor cells compared to hormone-positive tumors $(p=0.03)$. Similarly, tumors without bcl-2 protein expression had higher tumor levels of ANXA2 compared to tumor cells that were bcl-2 positive ( $p=0.05)$. Conclusion: ANXA2 stromal expression might play a key role in aggressive tumor phenotype associated with increased EMT CTCs release, however, other factors beyond ANXA2 are responsible for coagulation activation mediated by CTCs in breast cancer patients.

Breast cancer is the most common malignancy in women with an estimated 1.67 million new cases diagnosed worldwide in 2012, with Western Europe and North America having the highest incidence of 91 and 123 per 100,000, respectively $(1,2)$. Despite advances in screening, diagnosis and treatment, a significant portion of patients is diagnosed 
in advanced stages or develops metastatic disease. Circulating tumor cells (CTCs) are thought to have a crucial role in the metastatic cascade, tumor dissemination and progression. The prognostic value of CTCs was demonstrated by a number of trials for metastatic and primary breast cancer (3-5).

Annexin A2 (annexin II, ANXA2) is a phospholipid binding protein involved in fibrinolysis, cell proliferation, migration and metastatic dissemination. It is abundantly expressed in various tumor types, including breast cancer, where it is associated with an invasive phenotype. Several recent studies have implicated ANXA2 in neoangiogenesis, invasiveness and resistance to breast cancer treatment (6-11). ANXA2 is undetectable in normal ductal breast tissue. Increased expression is limited to proliferating ductal adenocarcinoma, ductal carcinoma in situ (DCIS) and the highly invasive/metastatic MDA-MB231 cell line in contrast to the noninvasive/nonmetastatic MCF-7 human breast cancer cell line (12). Presence of annexin A2 together with absence of annexin A1 correlated with poor response to neoadjuvant chemotherapy in breast cancer patients (13). Increased CTC count and ANXA2 are both poor prognostic factors in breast cancer and are linked to inferior survival $(5,14)$.

We previously showed that presence of any CTCs in the peripheral blood of advanced breast cancer patients is associated with increased risk of venous thrombosis (15). More recently, we found a positive correlation of plasma Ddimers, urokinase plasminogen activator proteins (uPA) and CTCs in patients with early, as well as those with metastatic breast cancer. Patients with early breast cancer and detected CTCs of any phenotype (epithelial or mesenchymal) had higher levels of plasma uPA, but we found no correlation between D-dimers, tissue factor or plasminogen activator inhibitor-1 (PAI-1) and uPA (16, 17). Plasminogen activators, tissue-type plasminogen activator (tPA) and uPA act on inactive plasminogen to produce active plasmin. Plasminogen receptors on the cell surface significantly increase plasmin generation while Annexin A2, cell anchoring protein of key plasminogen receptor protein S100A10, plays a central role in fibrinolysis and degradation of extracellular matrix proteins (18).

In this study, we hypothesized that there is a correlation between tumor and stromal ANXA2 expression in the presence of detectable CTCs. Moreover, we hypothesized, that the expression of ANXA2 on CTCs might be responsible for previously-observed coagulation activation (19).

\section{Patients and Methods}

This is an extension to our previous translational study (Protocol TRU-SK 002; Chair: M. Mego) approved by the Institutional Review Board (IRB) of the National Cancer Institute of Slovakia as previously reported $(20,21)$. The study included 101 patients with stages I-III primary breast cancer (PBC), who were undergoing definitive surgery for whom paraffin embedded tumor tissues were available. This is continuation of previous work, where other factors of coagulation (D-dimers, urokinase plasminogen activator and tissue factor) were investigated (16). From each patient peripheral blood (PB) was collected by venepuncture for CTCs detection and plasma analysis, and whenever possible, corresponding paraffinembedded tumor tissue. Each patient had given written consent form for the study and had received a complete diagnostic evaluation to exclude the presence of distant metastasis. Age-matched healthy women donors $(\mathrm{N}=60)$ without breast cancer were recruited and consented according to the IRB-approved protocol.

Detection of CTCs in PB. CTCs were detected in PB depleted of CD45+ leukocytes by quantitative real-time polymerase chain reaction (qRT-PCR) based assay, as described previously $(22,23)$. Briefly, PB samples were depleted of CD45+ leukocytes using the RossetteSep ${ }^{\mathrm{TM}}$ kit (StemCell Technologies, Vancouver, Canada) and isolated RNA from CD45-depleted PB samples was reversed transcribed to cDNA and subsequently subjected to qRT-PCR for expression of epithelial (CK19) or epithelial-mesenchymal transition (EMT) genes [TWIST1, SNAI1, SNAI2, zinc finger E-box-binding homeobox 1 (ZEB1)]. Patient samples with higher keratin-19 (CK19) gene transcripts than those of healthy donors were scored as epithelial CTCs positive (CTC_EP), while patient samples with higher EMT gene transcripts than those of healthy donors were scored as CTC_EMT positive.

Tumor pathology. Pathology review was conducted at the Department of Pathology, Faculty of Medicine, Comenius University, by two pathologists ( $\mathrm{ZC}$ and $\mathrm{PJ}$ ) associated with the study. Results of hormone receptors, HER2 status, B-cell lymphoma 2 (bcl-2) protein expression and protein p53 were reported either positive or negative on histopathology report without further quantification. Ki-67 labeling index was reported as percentage of cells with Ki-67 positive nuclear immunostaining. Hormone receptor status was defined as positive for either oestrogen receptor or progesterone receptor vs negative for both; $1 \%$ of cells positive for hormone receptor was used as the cut-off to define hormone receptor positivity and HER2 status (normal or amplified).

Diagnosis and tumor samples. The study included tumor specimens from 101 patients from previous work (15). For one patient from this study tumor specimen was not available for further analysis. All specimens were classified according to the WHO Classification of 2012. The block containing the most representative part of the tumor was identified by hematoxylin \& eosin (H\&E) microscopy and used for immunohistochemical (IHC) analysis.

Tissue microarray construction. According to tumor histology, one or two representative tumor areas were identified on H\&E sections. Sections were matched to their corresponding paraffin blocks (the donor blocks) and 3-mm diameter cores of the tumor were removed from these donor blocks with the multipurpose sampling tool Harris Uni-Core (Sigma-Aldrich, Steinheim, Germany) and inserted into the recipient master block. The recipient block was cut into 5- $\mu \mathrm{m}$ sections and the sections were transferred to coated slides.

Immunohistochemical (IHC) staining. Immunohistochemical staining of annexin A2 was performed according to the manufacturer's instructions; the positive control tissue staining was used for the verification of staining process suitability. Slides were 
deparaffinised and rehydrated in phosphate buffered saline solution (10 mM, pH 7.2). Antigen retrieval was not performed. Endogenous peroxidase activity was blocked by peroxidase-blocking reagent (S2003, integral part of DAKO EnVision FLEX kit, DAKO, Glostrup, Denmark).

The slides were subsequently incubated for one hour at room temperature with the primary mouse monoclonal antibody against Annexin II (Annexin II (E-11): sc-166762, Santa Cruz, Dallas, USA) diluted 1:50 in Dako REAL antibody diluent (S2022, Dako, Glostrup, Denmark) and immunostained using anti-mouse/antirabbit immuno-peroxidase polymer (EnVision FLEX/HRP, Dako, Glostrup, Denmark) for 30 minutes at room temperature, according to the manufacturer's instructions. For visualization, the diaminobenzidine substrate-chromogen solution was used (DAB, Dako, Glostrup, Denmark) for 5 minutes. Finally, the slides were counterstained with haematoxylin. As tumor associated stroma, the stromal cells between tumor nests, adjacent to tumor cells were evaluated. Cancer associated stroma was indicated by vimentinpositivity ( Monoclonal mouse anti-vimentin clone V9, code IR630, Dako, Glostrup, Denmark) and pan-cytokeratin-negativity (Monoclonal mouse anti-human clones AE1/AE3, code M3515, Dako, Glostrup, Denmark). Human gall bladder tissue served as positive control. As negative control, breast tissue was subjected to the same procedure omitting the primary antibody.

Immunohistochemical stain scoring. Tumor cores were independently assessed by two pathologists ( $\mathrm{ZC}$ and $\mathrm{PJ})$ who were blinded to clinico-pathological data. In cases of disagreement, the result was reached by consensus. The result of the IHC analyses was expressed by a weighted histoscore, evaluating both the percentage of positive cells (PP) and the membrane and cytoplasmic staining intensity (SI). Briefly, the proportion of cells with nuclear staining was multiplied by the intensity of staining to provide a score ranging from 0-300 and for sensitivity analysis we dichotomized it into low $(<150)$ and high $(\geq 150)$. The score was calculated as follows: Score $=(0 \times$ percentage not stained $)+(1 \times$ percentage weakly stained $)+(2 \times$ percentage moderately stained $)+(3 \times$ percentage strongly stained) (24).

Statistical analysis. Patient characteristics were tabulated. The patients' characteristics were summarized using the median (range) for continuous variables and frequency (percentage) for categorical variables. Normality of distribution was tested by the KolmogorovSmirnoff test. If normally distributed, sample means were tested by Student $t$-test or analysis of variance (ANOVA) with Bonferroni's or Tamhane's corrections depending on homogeneity of variance. The nonparametric Mann-Whitney $U$ or Kruskal-Wallis $\mathrm{H}$ test were used for non-normally distributed data. Pearson's or Spearman's correlation tests were used according to the normality of the data. Categorical data were tested by Fisher's exact test or Chi-square test. All $p$-Values presented are two-sided, and associations were considered significant if the $p$-Value was less or equal to 0.05 . Statistical analyses were performed using NCSS 2007 Data Analysis software (NCCS LLC, Kaysville, UT, USA).

\section{Results}

The study population consisted of 101 primary breast cancer patients with a median age of 60 years (range $=37-83$ years). Patients' characteristics are shown in Table I.
CTC detection. To determine overexpression of the EMTtranscription factor (TF) gene transcripts and CK19 in PBC patients, we compared the expression levels in patient samples with those of healthy donors. Relative to the highest levels of SNAI1 and ZEB1 transcripts detected in healthy donors samples, none of the patient samples overexpressed these gene transcripts. Among the patient samples, TWIST1, SNAI2, and CK19 transcripts were overexpressed in 3 (3.0\%), 13 (12.9\%) and $13(12.9 \%)$ samples, respectively. Totally, CTCs were detected in $25(24.6 \%)$ of patients. CTCs with only epithelial markers (CTC_EP) were present in PB of 13 (12.9\%) patients; CTCs with EMT phenotype (CTC_EMT) were present in 13 $(12.9 \%)$ of patients, while $1(1 \%)$ patient exhibited CTCs with both epithelial and mesenchymal phenotype (CK19 and SNAI2 overexpression) (Table I). In one patient sample, there was overlap in overexpression of EMT-TF gene transcripts (SNAI2 and TWIST1).

Correlation between CTC and Annexin A2 expression in tumor tissue and tumor associated stroma. There were no associations of tumor cell expressed ANXA2 and any subtype of CTCs (Table I). Mean \pm SEM (standard error of the mean) of weighted histoscore of ANXA2 expression was significantly higher in tumor cells negative for hormonal receptors compared to cancer cells positive for any hormonal receptor (148.6 \pm 28.0 vs. 76.4 vs. 11.2, $p=0.03)$. Similarly, tumors without bcl-2 protein expression had higher tumor levels of ANXA2 versus tumor cells bcl-2 positive (117.9 \pm 19.7 vs. $73.8 \pm 12.5, p=0.05)$.

In the next step, we have evaluated ANXA2 expression in tumor stroma and its association to CTC and other clinicopathological variables (Table II). Patients with CTC_EMT in the peripheral blood had significantly higher mean \pm SEM expression of ANXA2 in tumor associated stroma than those patients without CTC_EMT $(107.7 \pm 16.5$ $v s$. 64.8 $\pm 6.3, p=0.04)$. There was no correlation between stromal ANXA2 expression and epithelial type CTCs and/or other clinicopathological variables (Table II).

Expression of Annexin A2 on CTCs. To test the hypothesis that expression of the ANXA2 on CTCs could be responsible for coagulation activation, we analyzed expression of ANXA2 genes in peripheral blood enriched for CTCs (CD45-depleted fraction). We analyzed 30 samples (15 CTCs positive and 15 CTCs negative). We first looked at each sample if there was expression of genes indicating presence of CTC_EP and/or CTC_EMT and then pooled this outcome according to the expression of the ANXA2. We excluded from this analysis double positive samples (positive for CTC_EP and CTC_EMT). CTC_EP samples had a significantly higher expression of ANXA2 compared with those of CTC_EMT samples or CTC negative samples $(p=0.01)$ (Figure 1). 
Table I. Association between Annexin A2 in tumor cells and clinicopathological variables.

\begin{tabular}{|c|c|c|c|c|c|c|c|c|c|c|c|}
\hline \multirow[t]{3}{*}{ Variable } & \multirow{3}{*}{$\mathrm{N}$} & \multirow{3}{*}{$\%$} & \multicolumn{8}{|c|}{ Annexin A2 on tumor cells } & \multirow{3}{*}{$p$-Value } \\
\hline & & & \multirow[t]{2}{*}{ Mean } & \multirow[t]{2}{*}{ SEM } & \multirow[t]{2}{*}{ Median } & \multirow[t]{2}{*}{$p$-Value } & \multicolumn{2}{|c|}{ Low } & \multicolumn{2}{|c|}{ High } & \\
\hline & & & & & & & $\mathrm{N}$ & $\%$ & $\mathrm{~N}$ & $\%$ & \\
\hline All & 101 & 100.0 & 86.4 & 10.7 & 25 & NA & 74 & 100.0 & 27 & 100.0 & NA \\
\hline \multicolumn{12}{|l|}{ T-stage } \\
\hline 1 & 65 & 64.4 & 78.8 & 13.3 & 10 & 0.14 & 48 & 73.8 & 17 & 26.2 & 1.00 \\
\hline$>1$ & 36 & 35.6 & 100.1 & 17.9 & 87.5 & & 26 & 72.2 & 10 & 27.8 & \\
\hline \multicolumn{12}{|l|}{$\mathrm{N}$-stage } \\
\hline 0 & 59 & 58.4 & 75.5 & 13.9 & 10 & 0.14 & 45 & 76.3 & 13 & 22.0 & 0.26 \\
\hline$\geq 1$ & 42 & 41.6 & 101.8 & 16.5 & 60 & & 28 & 66.7 & 14 & 33.3 & \\
\hline \multicolumn{12}{|l|}{ Grade } \\
\hline 1 and 2 & 60 & 59.4 & 81.3 & 14.0 & 15 & 0.40 & 45 & 75.0 & 15 & 25.0 & 0.65 \\
\hline 3 & 39 & 38.6 & 2061.5 & 52.9 & 25 & & 27 & 69.2 & 12 & 30.8 & \\
\hline Unknown & 2 & 2.0 & & & & & & & & & \\
\hline \multicolumn{12}{|l|}{ Histology } \\
\hline Invasive ductal carcinoma & 85 & 84.2 & 93.5 & 11.6 & 30 & 0.25 & 59 & 69.4 & 26 & 30.6 & 0.06 \\
\hline Other & 16 & 15.8 & 49.1 & 26.6 & 5 & & 15 & 93.8 & 1 & 6.3 & \\
\hline \multicolumn{12}{|l|}{ Hormone receptor status } \\
\hline Negative for both & 14 & 13.9 & 148.6 & 28.0 & 200 & 0.03 & 6 & 42.9 & 8 & 57.1 & 0.0097 \\
\hline Positive for either & 87 & 86.1 & 76.4 & 11.2 & 20 & & 68 & 78.2 & 19 & 21.8 & \\
\hline \multicolumn{12}{|l|}{ HER2 status } \\
\hline Amplified & 16 & 15,8 & 83.4 & 26.9 & 15 & 0.82 & 12 & 75.0 & 4 & 25.0 & 1.00 \\
\hline Normal & 85 & 84.2 & 87.0 & 11.7 & 30 & & 62 & 72.9 & 23 & 27.1 & \\
\hline \multicolumn{12}{|l|}{ Ki 67 (cut-off 14\%) } \\
\hline Low & 50 & 49.5 & 70.9 & 15.1 & 35 & 0.37 & 41 & 82.0 & 9 & 18.0 & 0.07 \\
\hline High & 51 & 50.5 & 101.7 & 14.9 & 20 & & 33 & 64.7 & 18 & 35.3 & \\
\hline \multicolumn{12}{|l|}{ CTC_EP } \\
\hline Present & 13 & 12.9 & 58.1 & 29.7 & 20 & 0.59 & 11 & 84.6 & 2 & 15.4 & 0.51 \\
\hline Absent & 88 & 87.1 & 90.6 & 11.4 & 30 & & 63 & 71.6 & 25 & 28.4 & \\
\hline CTC EMT & & & & & & & & & & & \\
\hline Present & 13 & 12.9 & 102.3 & 29.8 & 30 & 0.81 & 8 & 61.5 & 5 & 38.5 & 0.33 \\
\hline Absent & 88 & 87.1 & 84.1 & 11.5 & 22 & & 66 & 75.0 & 22 & 25.0 & \\
\hline CTC Any & & & & & & & & & & & \\
\hline Present & 25 & 24.8 & 75.4 & 21.5 & 20 & 0.63 & 19 & 76.0 & 6 & 24.0 & 0.80 \\
\hline Absent & 76 & 75.2 & 90.1 & 12.3 & 40 & & 55 & 72.4 & 21 & 27.6 & \\
\hline LVI & & & & & & & & & & & \\
\hline Present & 24 & 23.8 & 81.3 & 22.0 & 23 & 0.71 & 17 & 70.8 & 7 & 29.2 & 0.80 \\
\hline Absent & 77 & 76.2 & 88.1 & 12.3 & 30 & & 57 & 74.0 & 20 & 26.0 & \\
\hline p53 & & & & & & & & & & & \\
\hline Present & 38 & 37.6 & 85.7 & 17.5 & 37.5 & 0.91 & 28 & 73.7 & 10 & 26.3 & 1.00 \\
\hline Absent & 63 & 62.4 & 86.9 & 13.6 & 20 & & 45 & 71.4 & 17 & 27.0 & \\
\hline BCL-2 & & & & & & & & & & & \\
\hline Present & 72 & 71.3 & 73.8 & 12.5 & 5 & 0.03 & 57 & 79.2 & 15 & 20.8 & 0.047 \\
\hline Absent & 29 & 28.7 & 117.9 & 19.7 & 100 & & 17 & 58.6 & 12 & 41.4 & \\
\hline Molecular subtype & & & & & & & & & & & \\
\hline Luminal A & 48 & 47.5 & 72.3 & 15.4 & 35 & 0.39 & 39 & 81.3 & 9 & 18.8 & 0.09 \\
\hline Luminal B & 24 & 23.8 & 89.4 & 21.8 & 10 & & 17 & 70.8 & 7 & 29.2 & \\
\hline HER2 & 16 & 15.8 & 83.4 & 26.7 & 15 & & 12 & 75.0 & 4 & 25.0 & \\
\hline $\mathrm{TN}$ & 13 & 12.9 & 136.9 & 29.6 & 200 & & 6 & 46.2 & 7 & 53.8 & \\
\hline
\end{tabular}

SEM, Standard error of the mean; CTC_EP, circulating tumor cells with epithelial phenotype; CTC EMT, circulating tumor cells with epithelialmesenchymal transition phenotype; LVI, lymphovascular invasion; Bcl-2, B-cell lymphoma 2; TN, triple negative.

\section{Discussion}

Previously, we have found an association between plasma Ddimers, uPA, PAI-1 and CTCs, indicating an activation of the coagulation cascade in early breast cancer patients (16). In this prospective translational study, we have not been able to show that the presence of CTC in PB of primary breast cancer patients is associated with ANXA2 expression in 
Table II. Association between Annexin 2A in tumor stroma and clinicopathological variables.

\begin{tabular}{|c|c|c|c|c|c|c|c|c|c|c|c|}
\hline \multirow[t]{3}{*}{ Variable } & \multirow{3}{*}{$\mathrm{N}$} & \multirow{3}{*}{$\%$} & \multicolumn{8}{|c|}{ Annexin A2 in tumor stroma } & \multirow{3}{*}{$p$-Value } \\
\hline & & & \multirow[t]{2}{*}{ Mean } & \multirow[t]{2}{*}{ SEM } & \multirow[t]{2}{*}{ Median } & \multirow[t]{2}{*}{$p$-Value } & \multicolumn{2}{|c|}{ Low } & \multicolumn{2}{|c|}{ High } & \\
\hline & & & & & & & $\mathrm{N}$ & $\%$ & $\mathrm{~N}$ & $\%$ & \\
\hline All & 101 & 100.0 & 70.3 & 6.1 & 100 & NA & 93 & 92.1 & 8 & 7.9 & NA \\
\hline \multicolumn{12}{|l|}{ T-stage } \\
\hline 1 & 65 & 64.4 & 69.2 & 7.6 & 100 & \multirow[t]{2}{*}{1.00} & 62 & 95.4 & 3 & 4.6 & \multirow[t]{2}{*}{0.13} \\
\hline$>1$ & 36 & 35.6 & 72.2 & 10.2 & 100 & & 31 & 86.1 & 5 & 13.9 & \\
\hline \multicolumn{12}{|l|}{$\mathrm{N}$-stage } \\
\hline 0 & 59 & 58.4 & 74.6 & 7.9 & 100 & \multirow[t]{2}{*}{0.38} & 53 & 89.8 & 5 & 8.5 & \multirow[t]{2}{*}{1.00} \\
\hline$\geq 1$ & 42 & 41.6 & 64.3 & 9.4 & 100 & & 39 & 92.9 & 3 & 7.1 & \\
\hline \multicolumn{12}{|l|}{ Grade } \\
\hline 1 and 2 & 60 & 59.4 & 63.3 & 7.8 & 100 & \multirow[t]{3}{*}{0.16} & 57 & 95.0 & 3 & 5.0 & 0.26 \\
\hline 3 & 39 & 38.6 & 82.1 & 9.7 & 100 & & 34 & 87.2 & 5 & 12.8 & \\
\hline Unknown & 2 & 2.0 & & & & & & & & & \\
\hline Histology & & & & & & & & & & & \\
\hline Invasive ductal carcinoma & 85 & 84.2 & 69.4 & 6.6 & 100 & 0.68 & 78 & 91.8 & 7 & 8.2 & 1.00 \\
\hline Other & 16 & 15.8 & 75.0 & 15.3 & 100 & & 15 & 93.8 & 1 & 6.3 & \\
\hline Hormone receptor status & & & & & & & & & & & \\
\hline Negative for both & 14 & 13.9 & 71.4 & 16.4 & 100 & 0.92 & 13 & 92.9 & 1 & 7.1 & 1.00 \\
\hline Positive for either & 87 & 86.1 & 70.1 & 6.6 & 100 & & 80 & 92.0 & 7 & 8.0 & \\
\hline HER2 status & & & & & & & & & & & \\
\hline Amplified & 16 & 15.8 & 72.9 & 6.6 & 100 & 0.37 & 16 & 100.0 & 0 & 0.0 & 0.35 \\
\hline Normal & 85 & 84.2 & 56.3 & 15.2 & 100 & & 77 & 90.6 & 8 & 9.4 & \\
\hline Ki 67 (cut-off 14\%) & & & & & & & & & & & \\
\hline Low & 50 & 49.5 & 66.0 & 8.6 & 100 & 0.44 & 46 & 92.0 & 4 & 8.0 & 1.00 \\
\hline High & 51 & 50.5 & 74.5 & 8.5 & 100 & & 47 & 92.2 & 4 & 7.8 & \\
\hline CTC_EP & & & & & & & & & & & \\
\hline Present & 13 & 12.9 & 70.5 & 6.5 & 100 & 0.92 & 13 & 100.0 & 0 & 0.0 & 0.38 \\
\hline Absent & 88 & 87.1 & 69.2 & 17.0 & 100 & & 80 & 90.9 & 8 & 9.1 & \\
\hline CTC EMT & & & & & & & & & & & \\
\hline Present & 13 & 12.9 & 107.7 & 16.5 & 100 & 0.04 & 9 & 69.2 & 4 & 30.8 & 0.009 \\
\hline Absent & 88 & 87.1 & 64.8 & 6.3 & 100 & & 84 & 95.5 & 4 & 4.5 & \\
\hline CTC Any & & & & & & & & & & & \\
\hline Present & 25 & 24.8 & 88.0 & 12.1 & 100 & 0.12 & 21 & 84.0 & 4 & 16.0 & 0.10 \\
\hline Absent & 76 & 75.2 & 64.5 & 6.9 & 100 & & 72 & 94.7 & 4 & 5.3 & \\
\hline LVI & & & & & & & & & & & \\
\hline Present & 24 & 23.8 & 67.5 & 7.0 & 100 & 0.38 & 22 & 91.7 & 2 & 8.3 & 1.00 \\
\hline Absent & 77 & 76.2 & 79.2 & 12.5 & 100 & & 71 & 92.2 & 6 & 7.8 & \\
\hline p53 & & & & & & & & & & & \\
\hline Present & 38 & 37.6 & 57.9 & 9.8 & 100 & 0.11 & 36 & 94.7 & 2 & 5.3 & 0.49 \\
\hline Absent & 63 & 62.4 & 77.8 & 7.6 & 100 & & 56 & 88.9 & 6 & 9.5 & \\
\hline BCL-2 & & & & & & & & & & & \\
\hline Present & 72 & 71.3 & 68.1 & 7.2 & 100 & 0.58 & 67 & 93.1 & 5 & 6.9 & 0.69 \\
\hline Absent & 29 & 28.7 & 75.9 & 11.3 & 100 & & 26 & 89.7 & 3 & 10.3 & \\
\hline Molecular subtype & & & & & & & & & & & \\
\hline Luminal A & 48 & 47.5 & 70.8 & 8.9 & 100 & 0.74 & 43 & 89.6 & 5 & 10.4 & 0.62 \\
\hline Luminal B & 24 & 23.8 & 79.2 & 12.5 & 100 & & 22 & 91.7 & 2 & 8.3 & \\
\hline HER2 & 16 & 15.8 & 56.3 & 15.4 & 100 & & 16 & 100.0 & 0 & 0.0 & \\
\hline $\mathrm{TN}$ & 13 & 12.9 & 69.2 & 17.0 & 100 & & 12 & 92.3 & 1 & 7.7 & \\
\hline
\end{tabular}

SEM, Standard error of the mean; CTC_EP, circulating tumor cells with epithelial phenotype; CTC EMT, circulating tumor cells with epithelialmesenchymal transition phenotype; LVI, lymphovascular invasion; Bcl-2, B-cell lymphoma 2; TN, triple negative.

tumor cells. Presence of ANXA2 is needed for plasminogen binding, plasmin generation and lysis of fibrin polymers. Moreover, plasminogen activators, tPA and uPA are necessary for plasmin activation. Our previous data have demonstrated that increased expression of uPA in plasma (but not in tumor tissue), has correlated with CTC in peripheral blood. However, we have not observed correlation between plasma/tumor uPA and D-dimer levels in that study. Similarly 


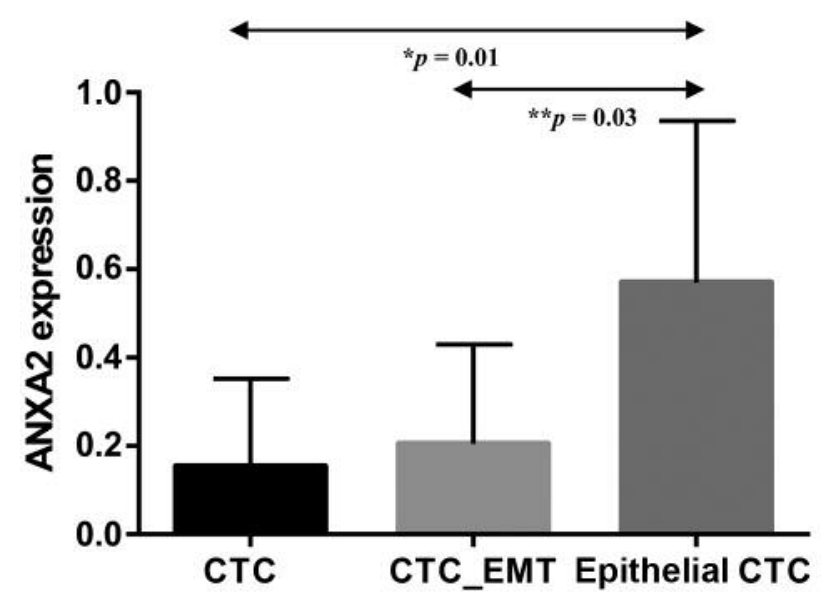

Figure 1. Differential expression of annexin A2 (ANXA2) on CTC subpopulations.

to uPA, ANXA2 is involved in fibrin degradation. Both of these negative findings (no association of tumor ANXA2 or tumor uPA and CTCs) might suggest that other factors play role in coagulation activation. It is plausible that analogous to circulating plasma uPA, secreted (circulating) form of ANXA2, might link CTCs to activation of hemostasis.

ANXA2 is activated in a calcium-dependent manner and forms heterotetramer with protein S100A10 (p11). S100A10 functions as plasminogen receptor, resulting in plasmin generation and fibrinolysis (18). Uninhibited plasmin generation in the tumor microenvironment can lead to extracellular matrix and basement membrane degradation. ANXA2 thus plays an important role in tumor migration and metastasis formation. Activation of epidermal growth factor receptor (EGFR) induces EMT in breast cancer $(25,26)$. ANXA2 is involved in EGFR signaling and its knockdown impaired EGF-induced epithelial to mesenchymal transition in breast cancer cells (14). Furthermore, ANXA2 depletion significantly reduced cell invasion and metastatic potential of breast cancer model in vivo. Similar findings of EGF enhanced ANXA2 expression and EMT promotion were observed in cervical cancer, pancreatic cancer and colon cancer cell lines $(19,27,28)$.

CTC_EMT are associated with stem-cell phenotype, chemoresistance and resistance to apoptosis (5). EMT switch is associated with enhanced migration and cell adhesion facilitating extravasion and neoangiogenesis (5). Therefore, we tested the hypothesis that EMT is accompanied by higher ANXA2 expression on CTCs. Our previous work suggested that uPA-system proteins (uPA, uPAR, PAI-1) are expressed on CTC_EP, but not on CTC_EMT (16). In this study, similarly higher expression of ANXA2 was on CTC_EP compared with CTC_EMT or CTC negative samples. It is likely that CTC_EP population harbor augmented fibrinolytic activity with increased plasmin generation at the cell surface. This might be responsible for pericellular proteolytic activity of CTC_EP. On one hand plasmin-mediated fibrinolysis might promote migration and intravasation of tumor cells; on the other, absence of fibrin may remove suitable stromal matrix and destabilize tumor stroma. The final outcome depends on the extracellular matrix composition and on the phenotype of individual tumor cells (29).

In addition, the importance of tumor stroma has long been recognized (30). Heterotypic interactions of tumor cells with adjacent stromal cell can induce expression of malignant cell phenotypes and promote extracellular matrix remodeling, cellular migration, neoangiogenesis, invasion, drug resistance and evasion of immunosurveillance (31). Indeed, it is thought that tumor-associated stroma is a prerequisite for tumor cell invasion and metastasis. We have found higher ANXA2 expression in tumor stroma, but not on tumor cells themselves, associated with increased CTC_EMT in peripheral blood. This finding might support the notion of tumor recruitment of non-cancerous stromal cells but recent evidence does not exclude possibility of transdifferentiation of tumor cells into stromal-like cells to aid tumor evasion $(32,33)$. Given the role of ANXA2 in angiogenesis and metalloproteinase activation, we postulate that observed stromal ANXA2 expression in our study might be responsible for extracellular matrix degradation and facilitation of CTC_EMT release from primary tumor into peripheral blood. Furthermore, we observed significantly higher ANXA2 expression on tumor cells in patients negative for hormonal receptors and bcl-2. Several trials have reported ANXA2 in breast cancer being associated with increased breast cancer proliferation and invasion $(6,7)$. In our experiment, we demonstrated that increased ANXA2 staining on breast cancer cells was strongly associated with well-known poor risk factors in breast cancer - hormone receptor negativity and bcl-2 absence. Hormone receptor negative subtypes includes basal-like and HER-2 subtypes of breast cancer, both viewed as more aggressive tumors, even in early breast cancer (34). These subtypes are often enriched for EMT markers, displaying stem cell characteristics (35).

BCL-2 is a suppressor of apoptosis, its expression paradoxically being associated with low-grade and estrogen receptor positive, slowly proliferating tumors with favorable prognosis. It is a powerful prognostic marker in ER positive, luminal A subtype of breast cancer (36). However, its expression in hormone receptor negative or triple negative (hormone and HER2 negative) patients is associated with unfavorable prognosis (37). It is thought that antiapoptotic properties of bcl-2 are more discernible in the absence of coexpressed hormone receptors. In our study, there was a positive correlation between high ANXA2 staining on tumor cells and bcl-negativity. The reason for it is not evident, as previous 
studies with ANXA2 siRNA and inhibitors of its glycosylation consistently demonstrated decreased bcl-2 expression, cell migration, proliferation and activating apoptosis $(10,38)$. It may well be that loss of bcl-2 is associated with molecular markers of poor prognosis, as previously reported for $\mathrm{p} 53$ and ANXA2 positivity in our study (39).

In conclusion, in this prospective study we did not find an association between ANXA2 on tumor cells and CTCs in early breast cancer patients. It is plausible that other factors might play a role in coagulation activation by CTCs. Moreover, we have demonstrated differential expression of the ANXA2 in CTC_EP and CTC_EMT, confirming the diverse roles of CTCs populations. It is likely that observed stromal ANXA2 expression associated with increased CTC_EMT in peripheral blood in our study might account for extracellular matrix degradation and CTC_EMT release from primary tumor. We have observed that higher expression of ANXA2 on tumor cells was associated with features of aggressive tumor phenotype, hormone receptor negativity and loss of bcl- 2 protein. The challenge for the future will be to identify the missing link between CTCs and coagulation activation and to investigate whether ANXA2 targeting could abrogate general poor prognosis of these patients.

\section{Ethics Approval}

Institutional Review Board, National Cancer Institute, Bratislava, Slovakia, Protocol TRU-SK 002).

\section{Conflicts of Interest}

On behalf of all the Authors, the senior author (MM) declares that there are no competing financial interests in relation to the work described in the article.

\section{Acknowledgements}

This publication is the result of the implementation of projects: no. 1/0724/11 funded by the Slovak Grant Agency VEGA.

\section{References}

1 Siegel RL, Miller KD and Jemal A: Cancer Statistics, 2017. CA Cancer J Clin 67: 7-30, 2017.

2 Ferlay J, Soerjomataram I, Dikshit R, Eser S, Mathers C, Rebelo M, Parkin DM, Forman D and Bray F: Cancer incidence and mortality worldwide: sources, methods and major patterns in GLOBOCAN 2012. Int J Cancer 136: E359-386, 2015.

3 Cristofanilli M, Budd GT, Ellis MJ, Stopeck A, Matera J, Miller MC, Reuben JM, Doyle GV, Allard WJ, Terstappen LW and Hayes DF: Circulating tumor cells, disease progression, and survival in metastatic breast cancer. N Engl J Med 351: 781-791, 2004.

4 Lucci A, Hall CS, Lodhi AK, Bhattacharyya A, Anderson AE, Xiao L, Bedrosian I, Kuerer HM and Krishnamurthy S: Circulating tumour cells in non-metastatic breast cancer: a prospective study. Lancet Oncol 13: 688-695, 2012.
5 Mego M, Mani SA and Cristofanilli M: Molecular mechanisms of metastasis in breast cancer - clinical applications. Nat Rev Clin Oncol 7: 693-701, 2010.

6 Sharma M, Ownbey RT and Sharma MC: Breast cancer cell surface annexin II induces cell migration and neoangiogenesis via tPA dependent plasmin generation. Exp Mol Pathol 88: 278-286, 2010.

7 Zhang J, Guo B, Zhang Y, Cao J and Chen T: Silencing of the annexin II gene down-regulates the levels of S100A10, c-Myc, and plasmin and inhibits breast cancer cell proliferation and invasion. Saudi Med J 31: 374-381, 2010.

8 Maji S, Chaudhary P, Akopova I, Nguyen PM, Hare RJ, Gryczynski I and Vishwanatha JK: Exosomal annexin II promotes angiogenesis and breast cancer metastasis. Mol Cancer Res 15: 93-105, 2017.

9 Sharma M, Blackman MR and Sharma MC: Antibody-directed neutralization of annexin II (ANX II) inhibits neoangiogenesis and human breast tumor growth in a xenograft model. Exp Mol Pathol 92: 175-184, 2012.

10 Shetty PK, Thamake SI, Biswas S, Johansson SL and Vishwanatha JK: Reciprocal regulation of annexin A2 and EGFR with Her-2 in Her-2 negative and herceptin-resistant breast cancer. PLoS One 7: e44299, 2012.

11 Hatoum D, Yagoub D, Ahadi A, Nassif NT and McGowan EM: Annexin/S100A Protein Family Regulation through p14ARF-p53 Activation: A Role in Cell Survival and Predicting Treatment Outcomes in Breast Cancer. PLoS One 12: e0169925, 2017.

12 Sharma MR, Koltowski L, Ownbey RT, Tuszynski GP and Sharma MC: Angiogenesis-associated protein annexin II in breast cancer: selective expression in invasive breast cancer and contribution to tumor invasion and progression. Exp Mol Pathol 81: 146-156, 2006

13 Chuthapisith S, Bean BE, Cowley G, Eremin JM, Samphao S, Layfield R, Kerr ID, Wiseman J, El-Sheemy M, Sreenivasan T and Eremin O: Annexins in human breast cancer: Possible predictors of pathological response to neoadjuvant chemotherapy. Eur J Cancer 45: 1274-1281, 2009.

14 Wang T, Yuan J, Zhang J, Tian R, Ji W, Zhou Y, Yang Y, Song W, Zhang F and Niu R: Anxa2 binds to STAT3 and promotes epithelial to mesenchymal transition in breast cancer cells. Oncotarget 6: 30975-30992, 2015.

15 Mego M, De Giorgi U, Broglio K, Dawood S, Valero V, Andreopoulou E, Handy B, Reuben JM and Cristofanilli M: Circulating tumour cells are associated with increased risk of venous thromboembolism in metastatic breast cancer patients. Br J Cancer 101: 1813-1816, 2009.

16 Mego M, Karaba M, Minarik G, Benca J, Sedlackova T, Tothova L, Vlkova B, Cierna Z, Janega P, Luha J, Gronesova P, Pindak D, Fridrichova I, Celec P, Reuben JM, Cristofanilli M and Mardiak J: Relationship between circulating tumor cells, blood coagulation, and urokinase-plasminogen-activator system in early breast cancer patients. Breast J 21: 155-160, 2015.

17 Mego M, Zuo Z, Gao H, Cohen EN, Giordano A, Tin S, Anfossi S, Jackson S, Woodward W, Ueno NT, Valero V, Alvarez RH, Hortobagyi GN, Khoury JD, Cristofanilli M and Reuben JM: Circulating tumour cells are linked to plasma D-dimer levels in patients with metastatic breast cancer. Thromb Haemost 113: 593-598, 2015.

18 Madureira PA, Surette AP, Phipps KD, Taboski MA, Miller VA and Waisman DM: The role of the annexin A2 heterotetramer in vascular fibrinolysis. Blood 118: 4789-4797, 2011. 
19 Cui L, Song J, Wu L, Cheng L, Chen A, Wang Y, Huang Y and Huang L: Role of Annexin A2 in the EGF-induced epithelialmesenchymal transition in human CaSki cells. Oncol Lett 13: 377-383, 2017.

20 Mego M, Cierna Z, Janega P, Karaba M, Minarik G, Benca J, Sedlackova T, Sieberova G, Gronesova P, Manasova D, Pindak D, Sufliarsky J, Danihel L, Reuben JM and Mardiak J: Relationship between circulating tumor cells and epithelial to mesenchymal transition in early breast cancer. BMC Cancer 15 : 533, 2015

21 Mego M, Cholujova D, Minarik G, Sedlackova T, Gronesova P, Karaba M, Benca J, Cingelova S, Cierna Z, Manasova D, Pindak D, Sufliarsky J, Cristofanilli M, Reuben JM and Mardiak J: CXCR4-SDF-1 interaction potentially mediates trafficking of circulating tumor cells in primary breast cancer. BMC Cancer 16: 127, 2016.

22 Mego M, Mani SA, Lee BN, Li C, Evans KW, Cohen EN, Gao H, Jackson SA, Giordano A, Hortobagyi GN, Cristofanilli M, Lucci A and Reuben JM: Expression of epithelial-mesenchymal transition-inducing transcription factors in primary breast cancer: The effect of neoadjuvant therapy. Int J Cancer 130: 808-816, 2012.

23 Cierna Z, Mego M, Janega P, Karaba M, Minarik G, Benca J, Sedlackova T, Cingelova S, Gronesova P, Manasova D, Pindak D, Sufliarsky J, Danihel L, Reuben JM and Mardiak J: Matrix metalloproteinase 1 and circulating tumor cells in early breast cancer. BMC Cancer 14: 472, 2014.

24 van Nes JG, de Kruijf EM, Putter H, Faratian D, Munro A, Campbell F, Smit VT, Liefers GJ, Kuppen PJ, van de Velde CJ and Bartlett JM: Co-expression of SNAIL and TWIST determines prognosis in estrogen receptor-positive early breast cancer patients. Breast Cancer Res Treat 133: 49-59, 2012.

$25 \mathrm{Kim}$ J, Kong J, Chang H, Kim H and Kim A: EGF induces epithelial-mesenchymal transition through phospho-Smad2/3Snail signaling pathway in breast cancer cells. Oncotarget 7 : 85021-85032, 2016.

26 Hardy KM, Booth BW, Hendrix MJ, Salomon DS and Strizzi L: ErbB/EGF signaling and EMT in mammary development and breast cancer. J Mammary Gland Biol Neoplasia 15: 191-199, 2010.

27 Zheng L, Foley K, Huang L, Leubner A, Mo G, Olino K, Edil BH, Mizuma M, Sharma R, Le DT, Anders RA, Illei PB, Van Eyk JE, Maitra A, Laheru D and Jaffee EM: Tyrosine 23 phosphorylation-dependent cell-surface localization of annexin A2 is required for invasion and metastases of pancreatic cancer. PLoS One 6: e19390, 2011.

28 Xiu D, Liu L, Qiao F, Yang H, Cui L and Liu G: Annexin A2 Coordinates STAT3 to regulate the invasion and migration of colorectal cancer cells in vitro. Gastroenterol Res Pract 2016: 3521453, 2016.

29 Palumbo JS, Kombrinck KW, Drew AF, Grimes TS, Kiser JH, Degen JL and Bugge TH: Fibrinogen is an important determinant of the metastatic potential of circulating tumor cells. Blood 96: 3302-3309, 2000.
30 Hanahan D and Weinberg RA: The hallmarks of cancer. Cell 100: 57-70, 2000.

31 Hanahan D and Coussens LM: Accessories to the crime: functions of cells recruited to the tumor microenvironment. Cancer Cell 21: 309-322, 2012.

32 Scully S, Francescone R, Faibish M, Bentley B, Taylor SL, Oh D, Schapiro R, Moral L, Yan W and Shao R: Transdifferentiation of glioblastoma stem-like cells into mural cells drives vasculogenic mimicry in glioblastomas. J Neurosci 32: 1295012960, 2012.

33 Cerasuolo M, Paris D, Iannotti FA, Melck D, Verde R, Mazzarella E, Motta A and Ligresti A: Neuroendocrine Transdifferentiation in Human Prostate Cancer Cells: An Integrated Approach. Cancer Res 75: 2975-2986, 2015.

34 Sorlie T, Perou CM, Tibshirani R, Aas T, Geisler S, Johnsen H, Hastie T, Eisen MB, van de Rijn M, Jeffrey SS, Thorsen T, Quist $\mathrm{H}$, Matese JC, Brown PO, Botstein D, Lonning PE and Borresen-Dale AL: Gene expression patterns of breast carcinomas distinguish tumor subclasses with clinical implications. Proc Natl Acad Sci USA 98: 10869-10874, 2001.

35 Hennessy BT, Gonzalez-Angulo AM, Stemke-Hale K, Gilcrease MZ, Krishnamurthy S, Lee JS, Fridlyand J, Sahin A, Agarwal R, Joy C, Liu W, Stivers D, Baggerly K, Carey M, Lluch A, Monteagudo C, He X, Weigman V, Fan C, Palazzo J, Hortobagyi GN, Nolden LK, Wang NJ, Valero V, Gray JW, Perou CM and Mills GB: Characterization of a naturally occurring breast cancer subset enriched in epithelial-to-mesenchymal transition and stem cell characteristics. Cancer Res 69: 4116-4124, 2009.

36 Eom YH, Kim HS, Lee A, Song BJ and Chae BJ: BCL2 as a Subtype-Specific Prognostic Marker for Breast Cancer. J Breast Cancer 19: 252-260, 2016.

37 Honma N, Horii R, Ito Y, Saji S, Younes M, Iwase T and Akiyama F: Differences in clinical importance of Bcl-2 in breast cancer according to hormone receptors status or adjuvant endocrine therapy. BMC Cancer 15: 698, 2015.

38 Shetty P, Bargale A, Patil BR, Mohan R, Dinesh US, Vishwanatha JK, Gai PB, Patil VS and Amsavardani TS: Cell surface interaction of annexin A2 and galectin-3 modulates epidermal growth factor receptor signaling in Her-2 negative breast cancer cells. Mol Cell Biochem 411: 221-233, 2016.

39 Krajewski S, Thor AD, Edgerton SM, Moore DH, Krajewska M and Reed JC: Analysis of Bax and Bcl-2 expression in p53immunopositive breast cancers. Clin Cancer Res 3: 199-208, 1997. 